\title{
El Carnaval de Cádiz como generador de infor- mación, opinión y entretenimiento. Un ejemplo de comunicación masiva
}

\author{
Ignacio SACALUGA RodRÍGUEZ \\ Universidad Europea de Madrid \\ ignacio.sacaluga@uem.es
}

\begin{abstract}
Resumen
El carnaval gaditano, desde sus orígenes hasta hoy, ha generado un volumen de información incalculable. Sus mensajes en forma de coplas, sus autores y las propias agrupaciones carnavalescas han ejercido de agentes socializadores con funciones similares a las de los medios de comunicación. Este periodismo cantado acumula unas particularidades históricas que le otorgan un marcado carácter contestatario. Su papel socializador, así como el de vigilante de los acontecimientos sociales, le han dotado de legitimidad popular para constituirse en un peculiar cuarto poder que, gracias a las redes sociales, trasciende el ámbito local para alcanzar la globalidad.
\end{abstract}

Palabras clave: Medios de comunicación; Carnaval de Cádiz; coplas; periodismo cantado.

The Carnival of Cadiz as an information, opinion and entertainment generator. A true example of massive communication

\begin{abstract}
The Carnival of Cadiz, has generated an invaluable volumen of information from its origins to nowadays. Its messages, taking the form of songs, its authors and also the carnival bands themselves have become socializing agents, performing functions similar to the ones performed by the social media. This "sung journalism" represents the sum of several historical features, which award the Carnival of Cadiz a strong controversial nature. Its socializing function, as well as its role as a "social events vigilante" (gatekeeper), have enjoyed popular legitimacy so as to turn into a peculiar "fourth state" that, thanks to its social networking, goes beyond the local sphere and reaches globality.
\end{abstract}

Key words: Social Media; Carnival of Cadiz, songs, "sung journalism".

\section{Referencia normalizada:}

Sacaluga Rodríguez, I. (2013) El Carnaval de Cádiz como generadores de infoación, opinión y entretenimiento. Un ejemplo de comunicación masiva. Historia y Comunicación Social. Vol. 18 No Especial Noviembre. Págs. 449-460.

Sumario: 1. Introducción. 2. Metodología. 3. Las agrupaciones carnavalescas. 4. El carnaval gaditano y sus similitudes con los mass media. 5. Conclusiones. 6. Referencias Bibliográficas. 7. Notas. 


\section{Introducción}

Es tal la cantidad de información que el Carnaval de Cádiz ha generado desde su creación que algunos autores le han adjudicado la etiqueta de "periodismo cantado": las agrupaciones carnavalescas narraban los acontecimientos más importantes acaecidos durante el año y lo hacían con una estructura musical propia del carnaval gaditano, ajustando la métrica y la rima de sus letras.

El Carnaval de Cádiz se ha transformado notablemente marcando política, artística y económicamente a la ciudad que lo vio nacer y evolucionando desde la oralidad de sus inicios hasta la viralidad de la era digital, un fenómeno que guarda similitudes en ciertos aspectos con la propia evolución de los mass media. Su particular trayectoria lo convierten en un vehículo de comunicación con un destacado impacto social.

Algunos elementos que denotan su importancia son: sus raíces italianas y afrocubanas, ya que en sus innumerables viajes por el atlántico², adoptó dejes del carnaval italiano:

Algo fácilmente explicable por la influencia genovesa que nuestra ciudad conoció [...] Las colonias italianas -y la más numerosa, genovesa- van a adquirir caracteres propios en nuestra ciudad hasta asimilarse en gaditanos, como demuestran apellidos tan gaditanos como Sopranis, Ravina, Lasquetty, etc. (Ramos Santana, 1985: 12).

La implicación de los ciudadanos en esta fiesta y las características histórico-sociales de la ciudad de Cádiz también fueron determinantes. Los medios de comunicación dieron una amplia cobertura informativa, en sus inicios la prensa, para seguirle la radio y la televisión hasta llegar a la actualidad con internet y las redes sociales.

El conocimiento del Carnaval de Cádiz y su implantación como algo más que un fenómeno local se vio potenciado por su extensión a lugares como Tenerife, Madrid o Barcelona así como fuera de nuestras fronteras a Uruguay donde hubo una fuerte presencia de emigrantes gaditanos.

Además, de la prensa local, la radio tomó un papel muy activo en su expansión. A través de las ondas se difundía lo más valorado de esta fiesta: sus coplas. Las emisoras hicieron llegar a los oyentes las primeras retransmisiones del Concurso Oficial de Agrupaciones Carnavalescas que evolucionaron hasta las emisiones de tarde y noche desde el Gran Teatro Falla o, en su defecto, desde el Teatro Andalucía.

Aunque la época dorada vendría propiciada por la televisión. El Concurso de Agrupaciones, o carnaval oficial, fue difundido a toda Andalucía y vía satélite a toda España, gracias a las cámaras, fundamentalmente, de Canal Sur. El carnaval se convirtió en un fenómeno nacional, pero realmente han sido las redes sociales y su proceso de viralización las que están generando su máxima expansión ya que ninguna de las etapas anteriores ha tenido tanto alcance como ésta.

Sin embargo, se hace necesaria una aproximación a sus agrupaciones para lograr entender la trascendencia de esta fiesta que tanto se diferencia de otras expresiones folclóricas y de cualquier otro carnaval del mundo. 


\section{Metodología}

Este artículo surge ante la necesidad de observar, medir y evaluar una realidad existente aunque no descompuesta para su análisis académico. Por tanto, se ha empleado el método empírico analítico para categorizar, hacer seguimientos, medir y evaluar. Se ha considerado este método adecuado ya que el objetivo del investigador es responder al análisis del hecho seleccionado.

Las técnicas utilizadas son principalmente cualitativas. Aunque también se incluyen técnicas cuantitativas como análisis e informes de obligada consulta para el objeto de estudio, tales como resultados estadísticos de audiencias televisivas de Sofres, los muestreos estadísticos del Instituto Nacional de Estadística (INE), etc.

En el proceso de documentación, se han elaborado fichas para facilitar el análisis y el seguimiento del objeto de estudio.

\section{Las agrupaciones carnavalescas}

El Reglamento establece que las cuatro modalidades de agrupaciones que pueden presentarse al Concurso Oficial de Agrupaciones Carnavalescas de 2013 (COAC 2013) $)^{3}$ son: Coros, Chirigotas, Comparsas y Cuartetos -a esta última la reconoce como "Trío, cuarteto o quinteto"-. Los primeros artículos del Reglamento establecen las modalidades según el número de miembros, la variedad de voces y el número y tipo de instrumentos, así como el número y tipo de piezas musicales que podrán utilizar durante la actuación. Salvo excepciones, el Reglamento no suele sufrir modificaciones de un año a otro y menos en cuanto a las características de las agrupaciones.

Las agrupaciones constituyen el elemento diferenciador y, se caracterizan fundamentalmente por la acidez, la mordacidad y la crítica de sus letras. Cada año se estima la participación de unas cuatro mil personas cantando, aproximadamente seiscientas músicas distintas y completamente originales, y unas nueve mil composiciones literarias diferentes. ${ }^{4}$ Todo ello conforma una muestra viva del contexto actual, la cotidianeidad y la actualidad.

\section{El carnaval gaditano y sus similitudes con los mass media}

Aunque las agrupaciones del carnaval gaditano no comparten todas las funciones clásicas de los mass media, su papel se asimila mucho al realizado por los medios de comunicación social. Comunican, forman y entretienen a una audiencia considerada masiva, por lo que actúan como agentes activos de la comunicación. Los acontecimientos sociales, económicos, políticos o culturales son contextualizados temporalmente por muchos seguidores del carnaval gaditano gracias a la agrupación 
carnavalesca que los mencionó en su repertorio. Como ejemplo, el 2 de agosto de 1990, la invasión iraquí del estado de Kuwait originó un conflicto bélico denominado La Guerra del Golfo Pérsico o también La Segunda Guerra del Golfo. Muchas letras del carnaval de 1991 estaban dedicadas al conflicto, como la que escribió el periodista Antonio Burgos para el coro A Venecia del Tirón, segundo premio del COAC. Estos son algunos versos de aquella copla:

"Lo escribe el Tío de la Tiza/ cuando agonizan nuestras colonias,/ [...]Ya los marineros de la fragata salen de Rota,/ y un padre me dice 'yo no comprendo esta decisión',/ y una madre llora, llora una hermana, llora una novia,/ suena la sirena del Vaporcito diciendo adiós. [...] Se marchan los marineros para una guerra sucia y temida./ El precio la gasolina defenderán,/ qué cruz la del andaluz para que un rico gane más./ [...] Al Golfo van nuestros hombres,/ y otros se quedan, yo sé sus nombres,/ yo sé sus nombres, quedan en tierra,/ que en esta guerra todos los golfos,/ todos los golfos, no han embarcado." 5

Esta letra pasó a formar parte de ese inmenso repertorio de coplas que siguen cantando los aficionados, a la postre capaces de contextualizar temporalmente aquella guerra gracias al recuerdo de este tango.

La ingente cantidad de coplas que atesora el Carnaval de Cádiz conforma una hemeroteca inmaterial de la realidad local, nacional e internacional que sitúa los hechos en tiempo, los descifra y los relega a la memoria colectiva.

Para entender el proceso comunicacional que ejerce el Carnaval de Cádiz, antes debemos delimitar aquello que entendemos por comunicación. La doctora Kathleen Reardon encuadra la comunicación dentro de los al menos cuatro medios por los que la gente aprende modos de conducta apropiados, que son: asociación, imitación, comunicación y persuasión.

La comunicación es algo más que la transmisión de ideas de una persona a otra. Es el medio a través del cual aprendemos quiénes somos y quiénes podríamos llegar a ser. [...] es nuestro vehículo para demostrar cómo hemos ajustado nuestros anteriores modos de conducta, inapropiados, para dar con las pautas del presente" (Reardon, 1991: 28).

Entre los diversos tipos de comunicación humana, la de masas se antoja indispensable para entender el fenómeno del Carnaval de Cádiz. La comunicación de masas se refiere al envío de mensajes a un público masivo mediante cualquier medio de carácter tecnológico, precisamente es este matiz el que caracteriza este tipo de comunicación.

Los investigadores John C. Merrill, John Lee y Edward Jay Friedlander, en su obra Medios de Comunicación Social, aluden a diferentes medios por los que el mensaje puede llegar a un público masivo: "la página escrita, la radio, la televisión, las películas, la pantalla, enormes carteles, hasta camisetas fabricadas en serie” (Merrill et al, 1992: 45). 
A mediados del siglo XX, autores como Bernard Berelson, destacan la dificultad de establecer cualquier tipo de predicción sobre los resultados de la comunicación. En ese sentido, se le detectó cierto relativismo al expresar que "algunas clases de comunicación, sobre cierta clase de temas que se presentan para llamar la atención de cierta clase de personas bajo determinadas circunstancias, tiene cierta clase de efectos" (Schramm, 1949: 500)6.

Todas las agrupaciones del carnaval de Cádiz son claros ejemplos de comunicación masiva, pues su repertorio, interpretado mediante coplas en un teatro, es transmitido para el área metropolitana, provincial o regional, e incluso internacional gracias a la radio y/o televisión, vía satélite o vía internet.

La actualidad está claramente presente en las letras ${ }^{7}$ que componen los repertorios de estas agrupaciones, pudiéndose clasificar fácilmente en las secciones características de un medio de comunicación: política -nacional o internacional-, economía, sociedad, cultura, deportes, ciencia/tecnología, comunicación o carnaval- siendo ésta una sección única de los medios de comunicación locales dentro del espacio geográfico de Cádiz-. ${ }^{8}$

Los elementos que constituyen el esquema básico de la comunicación y que se encuentran en cualquier proceso comunicativo los encontramos en el mensaje cantado que una agrupación carnavalesca envía a una audiencia masiva.

El emisor lanza un mensaje al receptor mediante un canal. En este mensaje intervienen la codificación y posterior decodificación que llevan a cabo el primero y segundo respectivamente. Para que exista comunicación, el código utilizado por el emisor exige que pueda ser comprendido por el receptor, "el proceso de pensamiento de quien envía el mensaje (su comunicación intrapersonal) es muy importante, y por supuesto cuando el decodificador recibe el mensaje [...] también requiere comunicación intrapersonal (pensamiento)" (Merrill et al, 1992: 49). Pueden aparecer ruidos que dificultan o interrumpen la comunicación, ya sean semánticos o mecánicos, durante la codificación y decodificación del mensaje. El ruido mecánico asume connotaciones físicas en cuanto al tipo de interrupción que supone, aunque el progreso tecnológico ha mejorado la calidad de las comunicaciones y este tipo de ruido está cada vez menos presente. Las peculiaridades del habla de Cádiz, junto con el hecho de que el mensaje vaya inserto en una estructura musical, constituyen una fuente de ruido semántico sobre todo para aquellas personas no familiarizadas con el acento gaditano.

Así mismo, cuando un mensaje, masivo o no, es enviado a un receptor, se produce una retroinformación o retroalimentación. El receptor puede añadir una respuesta al emisor que aporte información sobre la interpretación del mensaje.

Actualmente, los entornos web 2.0 y 3.0 permiten una retroinformación inmediata en el mismo instante en que se publica una noticia o un artículo de opinión, o durante la emisión en directo en un programa de televisión, e incluso cuando una agrupación de carnaval está actuando en el Concurso Oficial. Aún sin haber terminado de inter- 
pretar su copla, los usuarios de redes sociales ya están retroalimentando y retornando información sobre la lectura que hacen del mensaje.

También debemos hacer mención al efecto -o efectos- que produce el mensaje sobre el receptor, público o audiencia. Las diferentes corrientes sobre el estudio de la comunicación de masas han otorgado a los medios de comunicación estos efectos pudiendo distinguir distintos tipos de público. Cabe mencionar la teoría que diferencia al gran público del público especializado. Federico Boni, en su libro Teorías de los medios de comunicación, resume de manera muy certera cómo varía el tipo de público dependiendo del resultado que ejerzan sobre él los medios de comunicación:

"Dependiendo de que el poder de los medios de comunicación esté considerado fuerte, débil o "negociado", y dependiendo del contexto sociocultural en el que las instituciones mediáticas se insieren, el público será considerado: una masa, y será por tanto heterogéneo, anónimo, disperso, un grupo social, preexistente a los medios de comunicación, caracterizado por unos vínculos sociales y por una red de relaciones de interacción entre sus miembros" (Boni, 2008: 205).

Los autores del carnaval reconocen al público como un elemento decisivo en la actuación de una agrupación. El autor de agrupaciones del Carnaval de Cádiz, Juan Carlos Aragón, en su obra El Carnaval sin apellidos, apela a la sinceridad del público del teatro y que, "aunque a veces se equivoque, digo que no engaña porque expresa con sabia naturalidad las emociones que recibe desde el escenario" (Aragón Becerra, 2009: 157). En esa autoridad que Juan Carlos Aragón le concede al público se recogen las motivaciones de éste para adoptar una actitud empática con aquello que está viendo y escuchando, o bien, de crítica o de mera indiferencia.

Las críticas que elaboran las agrupaciones, aunque con notas de humor, se asemejan a las de las columnas de opinión de un periódico, o a las aportaciones de un contertulio televisivo o radiofónico, y cumplen una función similar: crear opinión. En ese sentido resulta significativo acudir a la clasificación que los autores Merrill, Lee y Friedlander elaboran del público, distinguiendo tres grupos según esta tipología actitudinal: "los incultos actitudinales", "los pragmáticos actitudinales" y "los intelectuales actitudinales". Los primeros "tienen una actitud negativa hacia las palabras, contra la lectura y la escritura y contra toda forma seria de difusión [...] Buscan en ellos la diversión y la excitación. Son consumidores superficiales [...] básicamente no les gusta leer". Son los más numerosos, pudiendo ser analfabetos o analfabetos funcionales. Los segundos, "los pragmáticos actitudinales", "son seres sociales, involucrados en asuntos sociales e interesados en conocer lo que sucede en su mundo [...] Puesto que lo que les interesa básicamente es el prestigio, [...] quieren estar informados sobre los asuntos internacionales, si no por otra razón, para impresionar a los demás con sus conocimientos". Son los favoritos de los medios de comunicación, son grandes consumidores de prensa, radio, televisión, música, etc. Y el tercer grupo, el de "los intelectuales actitudinales", son un grupo que se preocupa por aspectos relacionados con la intelectualidad, la filosofía y huye de la frivolidad de los mensajes masivos así como todo lo que conecte con lo mundano. Lo consideran "el segmento más pequeño del público. No son necesariamente los más inteligentes, 
pero tienen una actitud intelectual", ya que, en definitiva, "un intelectual es un pensador, un amante de los placeres estéticos y no encaja con el concepto de masa" (Merrill et al, 1992: 93-95).

Entre el público del carnaval puede encontrarse ese primer grupo de "incultos actitudinales", son los que buscan el entretenimiento, no buscan realizar un análisis profundo del mensaje que transmiten las agrupaciones. Según describe el periodista gaditano Fernando Santiago, es un público que "aplaude lo que le echen. Lo mismo se pone en pie para defender una cosa que la contraria". La música, la fuerza dialéctica con la que pronuncian ciertas palabras o expresiones, la rima y la gestualidad -un ingrediente de gran importancia- son recursos incluidos en los mensajes de las agrupaciones y que aumentan la carga emotiva de las propias letras. Estos elementos añadidos explicarían que este primer grupo de público, reaccionara con la misma vehemencia ante un mensaje en pro de cierta doctrina y otro en pro de la contraria, al no estar interesado en la reflexión y el juicio.

Respecto al segundo grupo, el de los "pragmáticos actitudinales", también pueden establecerse conexiones con cierto tipo de público receptor de los mensajes del carnaval. A este segundo grupo le prima la necesidad de estar informado, el interés por la actualidad del mundo e incluso el obtener prestigio a través de la acumulación de información. Se trata del tipo de público preferido por las agrupaciones, un tipo de público que huye de las letras populistas y que busca mecanismos de creatividad, lógica y genialidad. "Hasta hace relativamente pocas ediciones, cuando el público se ponía en pie con una agrupación, dicha agrupación tenía garantizada -como mínimola Final" (Aragón Becerra, 2009: 158). Esta afirmación de Juan Carlos Aragón conecta la opinión de un público más reflexivo con la fría ecuanimidad que se le presupone al propio jurado oficial.

El grupo de "los intelectuales actitudinales" coincide con una minoría entre el público de las agrupaciones. Un tipo de audiencia que busca la excelencia, la misma creatividad presente en otros géneros de la cultura que mezcla los ingredientes necesarios para elevarla a categorías superiores: en el texto de una buena obra de teatro o guión de cine o una buena columna de opinión. Una de las figuras significativas del humor absurdo, Javier Cansado, reconoce la calidad de determinados contenidos del carnaval.

La gente que critica el Carnaval de Cádiz generalmente siempre dice lo mismo, que el Carnaval de Cádiz es una cosa zafia, es un humor de decir "cojones", todo es humor sexual y todo es muy primario, y sí, también lo hay porque no voy a decir yo que no, pero hay cosas que son muy sofisticadas, bueno sofisticadas no, elevadas, cosas que están muy desarrolladas. ${ }^{10}$

Gerardo Pastor, investigador de la Universidad Pontificia de Salamanca, acota el verdadero proceso comunicativo a la situación en que el receptor reacciona a la provocación. "En la comunicación de masas analizar el efecto o resultado persuasivo es de trascendental importancia para revalidar géneros, autores, guionistas, secciones o para eliminarlos de la programación. Y así, los estudios sobre difusión de prensa, 
los análisis de audiencia, revelan diversas y posibles reacciones del público" (Pastor, 2012: 152). Son reacciones que entorpecerían en gran medida el propósito de la comunicación. Entre esas posibles reacciones, el profesor Gerardo Pastor destaca "el rechazo del mensaje o del canal, [...] la descalificación de la fuente por incompetente, $[\ldots]$ la suspensión del juicio hasta conseguir información adicional, $[\ldots]$ la distorsión del mensaje para adecuarlo a los propios puntos de vista, [...] el reforzamiento de actitudes, ideas, valores u opiniones [...] o el cambio en el sentido propuesto por la fuente del mensaje." (Pastor, 2012: 152).

La resistencia que el público puede generar se produce también en la audiencia de las agrupaciones carnavalescas. Según el autor Juan Carlos Aragón se produce el fenómeno "hooligans" en una parte de la audiencia, y al igual que en un sector del público se produce una admiración desmesurada por ciertas agrupaciones, también desmesurada puede resultar la animadversión por otras, produciéndose un rechazo hacia el propio mensaje.

Buena parte de las funciones clásicas que Harold Lasswell describió en su análisis de las mismas -en 1948- dentro de una obra coral editada por Lyman Bryson, son compartidas por los medios de comunicación y las agrupaciones carnavalescas. Fue el sociólogo Charles Wright, en su obra Mass communication: A sociological perspective, quien pulió posteriormente este trabajo. Para ambos autores los medios de comunicación actúan como vigilantes del medio, como intérpretes de los hechos ante la sociedad (lo denominan "correlación de las partes") y como vehículos de transmisión cultural.

Los autores del carnaval y por extensión las agrupaciones cumplen con una función de vigilancia como informadores de la sociedad ya que los repertorios de sus coplas se refieren, en su mayoría, a hechos que son o han sido noticia a lo largo del año. Es el género interpretativo el protagonista del carnaval gaditano ya que a la exposición de datos y hechos noticiosos suele seguirle una explicación de estos extrayendo a menudo causas y posibles resultados. ${ }^{11}$ La función de transmitir un legado social es con frecuencia la menos considerada. Es generadora de cultura y transmisora de valores de la sociedad gaditana e incluso, de la andaluza o la española; además de constituir una hemeroteca musical de los hechos más importantes ocurridos desde la existencia, al menos, del Concurso Oficial de Agrupaciones.

Charles Wright agregó la función del entretenimiento ${ }^{12}$, una apreciación que se encuentra alojada en el propio ADN de los media y también en el de las agrupaciones del carnaval. Ejemplo de ello son las audiencias que genera el Concurso en Canal Sur Televisión. La final del COAC 2013 supuso para la cadena un 23,5\% de cuota media de pantalla, seis puntos por encima de la media del día. Además este dato posicionó a Canal Sur como líder absoluto de la parrilla andaluza y líder también entre todas las autonómicas. ${ }^{13}$

Otra muestra del éxito de la retransmisión del Concurso de Agrupaciones como espacio de entretenimiento es su duración que, dependiendo del año, alcanza entre 
las seis y las ocho horas de media. Concretamente la de 2013 duró algo más de siete horas. ${ }^{14}$

Un argumento más en el sentido anteriormente expuesto lo vemos en el siguiente gráfico (la evolución positiva del share generado durante la retransmisión de las Finales del COAC entre 2010 y 2013).

Evolución anual del share del Carnaval de Cádiz (2010-2013)

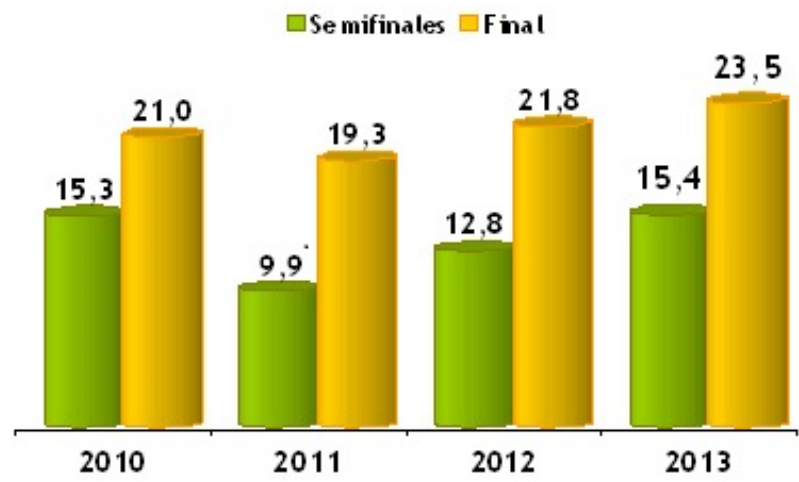

Fuente: http://blogs.canalsur.es/saladeprensa

La función complementaria de los medios de comunicación respecto a los gobiernos se puede ejercer desde distintos prismas: como adversarios respecto del poder político, desde una posición esclavizadora, o bien, como sujeto independiente. Este planteamiento podemos verlo reflejado en las agrupaciones del carnaval gaditano, que por un lado, dan información no siempre destacada en los medios de comunicación -por no responder a relaciones viciadas de poder con la administración o con grupos de comunicación-, y por otro, pueden llegar a generar movimientos políticos en la administración local gaditana por temor a las consecuencias propagandísticas de las coplas del carnaval.

\section{Conclusiones}

Las agrupaciones del carnaval gaditano han asumido, casi desde sus inicios, unas funciones similares a las de los medios de comunicación social.

Originariamente fueron transmisores de informaciones, recogidas de la prensa o no, relacionadas con la realidad social, política y económica de la ciudad, del país e incluso del ámbito internacional. 
Al igual que los medios convencionales, el carnaval se ha visto influido o sometido por los diferentes regímenes políticos establecidos fundamentalmente durante los siglos XIX y XX. Pese a los distintos grados de censura y a la prohibición franquista de los carnavales, el carnaval gaditano ha logrado cumplir su función informadora, formadora y generadora de entretenimiento; así como la de vigilantes, intérpretes y transmisores de un legado cultural.

Actualmente, con el entorno web 2.0 y 3.0, las agrupaciones han adquirido dimensiones que requieren un análisis en profundidad.

\section{Referencias bibliográficas}

Libros

ARAGÓN BECERRA, Juan Carlos (2010). El Carnaval sin apellidos. Un arte mayor para una chusma selecta. Cádiz: Autoedición Juan Carlos Aragón Becerra.

BONI, Federico (2008). Teorías de la comunicación. Barcelona: Universitat Autònoma de Barcelona.

BRYSON, Lyman (ed.) (1948). The Communication of ideas. Nueva York: Harper and Brothers.

LLOMPART BELLO, Bartolomé (2002). El Cádiz de Bartolomé Llompart. De Ayer a hoy. Cádiz: Asociación de la Prensa de Cádiz.

McQUAIL, Denis (1997). Audience Analysis. Thousand Oaks: SAGE Publications.

MERRILL, John C; LEE, John; FRIEDLANDER, Edward J. (1992): Medios de comunicación social. Teoría y práctica en Estados Unidos y en el mundo. Madrid: Fundación Germán Sánchez Ruipérez.

OSUNA GARCÍA, Javier (2009). El periodismo en tiempos de carnaval. 1763-2005. Cádiz: Quorum Editores.

RAMOS SANTANA, Alberto (1985). Historia del Carnaval de Cádiz. Cádiz: Ediciones de la Caja de Ahorros de Cádiz.

REARDON, Kathleen K. (1991). La persuasión en la comunicación. Teoría y contexto. Barcelona: Paidós Comunicación.

Artículos

BERELSON, Bernard (2008). "Mass Communication and Public Opinion", en SCHRAMM, Wilbur (ed.). Mass Communication. University of Illinois Press. Urbana.

PASTOR, Gerardo (2012). "Psicología de la comunicación", en CANTAVELLA, Juan y SERRANO, José Francisco (eds.). Enciclopedia de la comunicación. Madrid: CEU ediciones.

WRIGHT, Charles (1986). "Análisis funcional y comunicación de masas", en DE MORAGAS SPÀ, Miquel (ed.). Sociología de la comunicación de masas. Vol 2. Gustavo Gili. Barcelona. 


\section{Publicaciones web}

REGLAMENTO PARA EL CONCURSO OFICIAL DE AGRUPACIONES COAC (2013), en Aula de Cultura del Carnaval de Cádiz. Disponible en: http://auladeculturadelcarnavaldecadiz.com/Imagenes 1/PDF/2013/REGLAMENTO\%20 ADULTOS\%20COAC\%202013.pdf. Consultado el 21 de septiembre de 2012.

Comunicaciones personales al autor del artículo

CÁRDENAS, Francisco. (Comunicación Personal). Noviembre 2008. CANSADO, Javier. (Comunicación Personal). Noviembre 2008.

\section{Notas}

1 Aunque esta etiqueta se ha utilizado de manera generalizada, hasta el punto de institucionalizarse en la cultura popular, parece- aunque no se ha logrado demostrar- que fue el periodista Bartolomé Llompart el primero que se refirió al carnaval gaditano como un "periodismo cantado".

2 Durante el siglo XVIII Cádiz gozaba del monopolio del comercio con América, algo que otorgó, según el investigador Alberto Ramos Santana "tales niveles de riqueza, que la centuria dieciochesca se ha podido denominar el siglo de oro gaditano."

3 Aula de Cultura del Carnaval de Cádiz. Disponible en: http://www.auladeculturadelcarnavaldecadiz. com. Consultado el 1 de septiembre de 2013.

4 Francisco Cárdenas Ruso. (Comunicación Personal). Noviembre 2008.

5 Tango titulado "Lo escribe el Tío de la Tiza", del Coro A Venecia del Tirón (1991). Disponible en: http://www.antonioburgos.com/coplas/carnaval/venecia/golfo.html. Consultado el 1 de septiembre de 2013.

6 En el artículo de Bernard Berelson titulado "Communication and Public Opinion" integrado en el manual Mass Communication cuyo editor es Wilbur Schramm.

7 Entendiendo letras como "coplas", nomenclatura genérica que alberga el pasodoble, el tango o el cuplé.

8 Sirvan estos dos ejemplos, entre muchos otros, que responden a los dos medios escritos de mayor tirada: Diario de Cádiz (del Grupo Joly) y La Voz de Cádiz (del Grupo Voz). Disponible en: http:// www.diariodecadiz.es/carnavalcadiz2013. Consultado el 1 de septiembre de 2013. Disponible en: http://carnaval.lavozdigital.es/. Consultado el 1 de septiembre de 2013.

9 El periodista Fernando Santiago así lo expone en un artículo titulado "14 husillos", publicado en la sección de opinión de Diario de Cádiz. Información publicada por Diario de Cádiz el 17-02-2011. Disponible en: http://www.diariodecadiz.es/article/opinion/906771/husillos.html. Consultado el 3 de septiembre de 2013.

10 Javier Cansado. (Comunicación Personal). Noviembre 2008.

11 Casi cualquier copla elegida al azar podría demostrarlo. La nota a pie número 8 corresponde al fragmento de un tango escrito por Antonio Burgos donde también puede constatarse.

12 Charles Wright se refiere a la función del entretenimiento en su Análisis funcional y comunicación de masas (De Moragas, 1986: 69-90). 
13 Disponible en: http://blogs.canalsur.es/saladeprensa/2013/02/11/canal-sur-television-lider-de-audiencia-con-la-retransmision-de-la-gran-final-del-carnaval-de-cadiz/. Consultado el 10 de septiembre de 2013.

14 Ídem.

\section{El autor}

Ignacio Sacaluga Rodríguez es profesor universitario, periodista, guionista, director de programas de televisión y realizador de documentales. Imparte clases en la Facultad de Artes y Comunicación de la Universidad Europea de Madrid desde 2006. En estos momentos se encuentra concluyendo su tesis doctoral.

En el ámbito profesional ha creado diversos formatos televisivos $\mathrm{y}$ ha dirigido proyectos culturales audiovisuales de distinta índole, el último 'La Cara B', en streaming, presentado José María Íñigo y Forges; también ha dirigido el programa de cultura "Escenario Madrid" en Telemadrid durante cuatro temporadas. Ha trabajado durante 13 años en el área de cultura de Telemadrid y laOtra. Ha dirigido diversas series de documentales de temática social y cultural. Ha presentado el programa Básico de Telemadrid donde ha entrevistado a numerosas personalidades de las artes, el teatro, la música, la literatura y la ciencia. Ha trabajado también para Antena3 TV, Televisión Castilla y León, Onda Jerez TV, Cadena Ser, etc.

Ha dirigido el largometraje documental 'Febrero. Cuando la vida es Carnaval' por el que obtuvo el Premio Nacional del Festival Internacional de Cine Documental y Musical de Barcelona, In-Edit Beefeater 2009, entre otros reconocimientos. 